\title{
RESEARCH ON THE NORMATIVE PROVISION OF THE EDUCATION SYSTEM WITH A FOCUS ON THE SUBJECT PHYSICAL EDUCATION AND SPORT
}

\author{
K. Naydenova* \\ Department of Theory of Physical Education. National Sports Academy „Vassil Levski“, \\ Sofia, Bulgaria
}

\begin{abstract}
In the last four years there have been a number of changes in the field of secondary education in the country, which are basically of a normative nature. Following the processes of regulation and functioning of the education system in the country, we decided to study the basic normative documents that regulate and have relation to the subject Physical Education and Sport. The method by which we conducted the study is research and analysis of literary and documentary sources. As a result of the research carried out, we have identified changes in the structure of the educational system, which have an immense impact on the state of the educational requirements and the content of the subject curricula. The conclusions of the conducted survey are as follows:

1. The already approved legal framework, which regulates the secondary education system in the country, is based on a qualitatively new approach in education, which leads to both structural and functional changes in the system.

2. The subject of Physical Education and Sports remains obligatory for all pupils at all stages and levels of the education system, except for those who are trained under the "Dual Training" system in the second high school stage.

3. In the approved curricula of Physical Education and Sport, there are many repetitions of the learning content in the different stages and grades, which is a prerequisite for loss of training hours and non-observance of the principles and particularities of the training in motor activities.
\end{abstract}

Key words: school, training, laws

\section{INTRODUCTION}

One of the subjects studied by all students in the system of Bulgarian secondary education is "Physical Education and Sport". The need for this is due to the multilateral impact that can be done by its means and methods. For example, S. Ivanov et al. (1996) (2) believe that the motion and physical education at pre-school age is important "not only for the physical but also for the psychological development" of the child. As a result of these effects, physical education is burdened is charged with a number of responsibilities related to the overall development of the student's personality. The

*Correspondence to: Korneliya Naydenova, Department of Theory of Physical Education. National Sports Academy ,, Vassil Levski“, Sofia, Bulgaria, Studentski grad, floor 4, office 411, phone: 00359892299811, e-mail: knaidenova.nsa@gmail.com formation of the personality is achieved not only by the effects on purely physical and motor side of the student, as we most of the time expect from the physical education, but also those aimed at forming and improving different cognitive processes. The practical realization of the impacts considered is possible by providing a complex approach in the planning and realization of the training on the subject. The correct realization of these two aspects of the training is possible if we know and observe the requirements of the normative basis which regulates the relations in the physical education as a subject of study.

Given that physical education is an integral part of the education system, we should also take into account the fact that it evolves and changes depending on the dynamics and the peculiarities of the changes in this system. The 
education system, in turn, follows the requirements and trends of social development. Any change in a particular system is reflected by greater or lesser force on each of its subsystems. In this case, we can look at the three-way connection society-educationphysical education as elements of a system. L. Borissov (2017) (1) views this link by summarizing that "the dynamically changing social conditions require the updating of the content of SER, curricula and curricula."

Thus, as a result of a number of societal changes between 1989 and 2019, education in Bulgaria has undergone a number of changes and reforms. The first is immediately after the transition and the change of the social and political system in the country. The basis is the promulgated in State Gazette, no. 86 of 18.10.1991 Act on National Education (3). The same law regulates public relations in education until 2016. During the 15-year period it underwent a total of 36 repairs. With one of these amendments from State Gazette, no. 36 of 1998, in compliance with the requirements and tendencies of the European Educational Area in our country, the State Educational Requirements are introduced. They determine the levels of general education and vocational training required, and so called educational minimum. The latest educational reform in the country became a reality with the adoption of the Preschool and School Education Act, promulgated in State Gazette, issue no. 79 of 13.10.2015 and entered into force on 1 August 2016) (4)

These changes have greatly affected the educational subject Physical Education and Sports. In purely practical terms, one of the most ineffective changes we can point out is the lack of digital scores for pupils during the school years 1992-1993, 1993-1994 and 19941995, which has led to a decline in the authority of the subject. During this period, students' achievements are rated "pass" and "fail," which demotivates participants in the educational process. Another change in the subject and the motor activity of the students is the introduction of the third hour of "Physical Education and Sports" in 2004. With amendments to Art. 16 of the Law on the level of education, the general educational minimum and the curriculum.

\section{METHODOLOGY}

In view of what has been said so far, we have set a goal to study the basic normative documents that regulate and relate to the subject of Physical Education and Sport and to determine their impact on the subject. In order to achieve this goal, we set the following tasks:

1 . Research and analysis of literary sources.

2. Analysis of the functioning of the educational system.

3. Discovering the influences of the implemented normative changes on the functioning of the subject "Physical education and sport".

The subject of our study is the numerous laws and regulations in the sphere of education, and its subject is the influence they have on the studied subject. The main method we used in the implementation of this study is the study and analysis of literary and documentary sources.

\section{Exposition}

To track the impact of changes in the country's education system over this particular subject, it is appropriate to first determine its place in the structure of this system. The many changes in the legal framework of the education system over the past 30 years have led to several significant changes in the structure and functions of the educational system in the country. In practical terms, these are the content of the individual stages and degrees of education, the real opportunity to complete secondary education at the age of 16 , profile and dual learning.

In the structural plan there is a significant change in the educational system in the country, which is related to the shortening of the lower secondary level of the basic education with one school year, as this stage covers the classes V to VII. This change leads to an increase of the middle educational level with one academic year. As a result of this and of the possibility to complete secondary education at the age of 16 , the secondary education is divided into first and second high school stage, which are realized respectively in classes VIII to X and XI to XII. These changes are reflected in Table 1, according to the texts of Article 8, para. 1 and 2, Art. 1, 2 and 3 of the Pre-school and School Education Act (4).

Apart from purely structural changes and functionalities, they are directly related to the learning process and, in particular, to physical education and sport training. The introduction of profiled training according to Art. 74, para. 3 of the Preschool and School Education Act affirms 12 profiles at the high school stage. One of them is also "Physical education and 
sports". Profiled education is acquired in a second high school stage through a set of profiling subjects. According to the Act of Preschool and School Education, two of these subjects are determined by the State Educational Standard for Profile education and the rest are determined by the school through the curriculum.

According to art. 2, para 7, item 11 (4), the mandatory profile subjects for the profile "Physical education and sport" are "Physical education and sport" and "Biology and health education".

Table 1. Structure of the educational system in Bulgaria

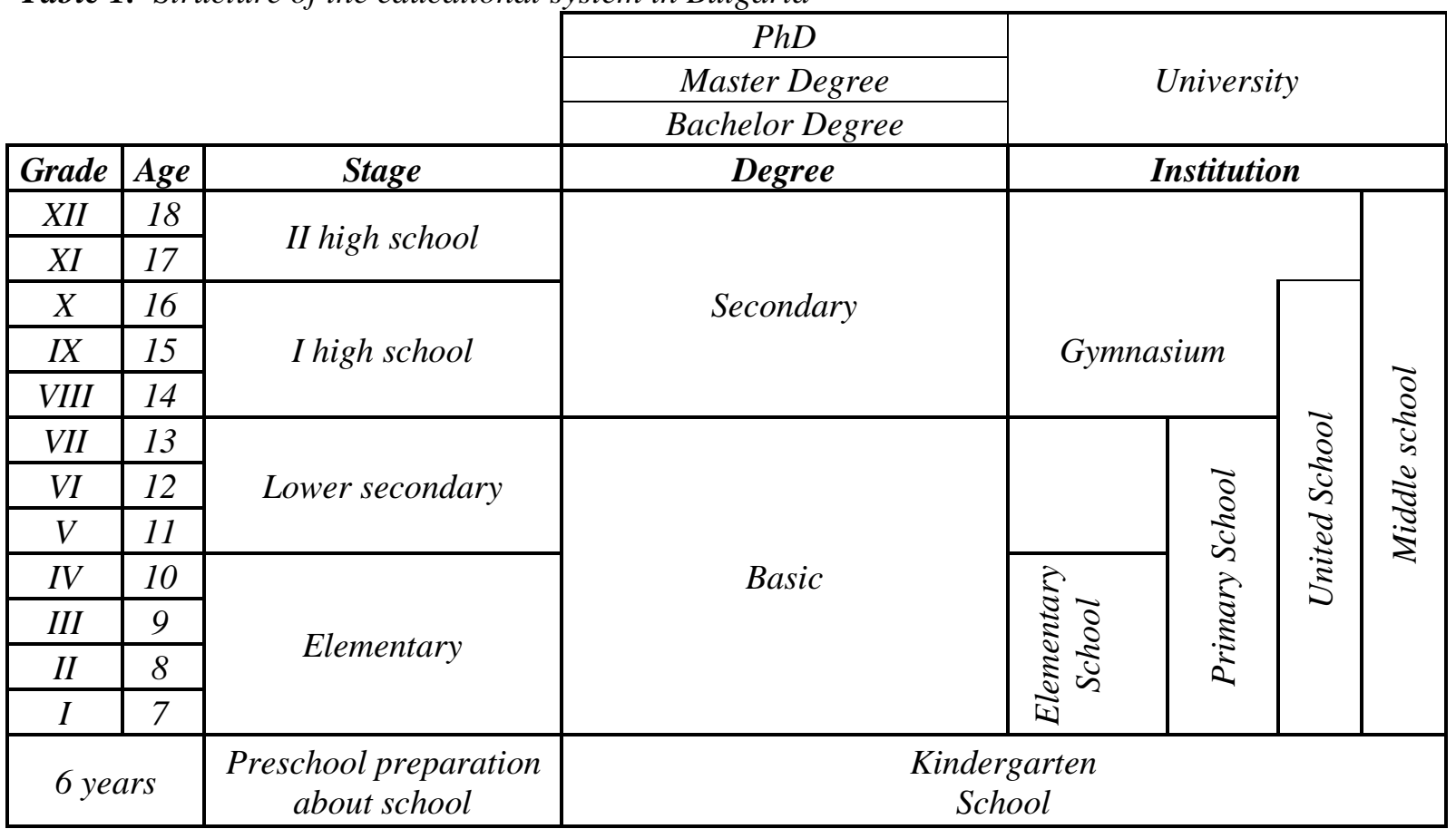

Completion of the education is accomplished by covering the "State graduation examinations" on the subjects "Bulgarian Language and Literature" and "Biology and Health Education". Or the grads who acquire the "Physical Education and Sports" profile can not attend a graduation exam on the profile discipline because the act does not provide such an examination. Another paradox of Act of Preschool and School Education (4) is the lack of the subject of "Physical Education and Sports" for students who will be educated in a dual form of education. In addition, there is one of the amendments to the Ordinance amending and supplementing Ordinance No. 5 of 2015 (5) on general education promulgated in State Gazette, issue no. 80 of 28.09.2018 and in force since 28.09.2018. In the annex to this Ordinance are added texts that define the state educational standard for the subject "Physical education and sport" for the content in the second high school stage which, unlike of the other subjects studied at this stage so far did not exist in the document. With the addition of these texts, a new controversy arises, which is related to the separation of the content of elective and compulsory modules, which is divided into obligatory and optional areas of learning content by the end of the first element of the upper secondary school. The separation of the modules' content does not correspond to the substance and content of the document in question.

In essence, the training on "Physical Education and Sport" is regulated by the curriculum for the respective class. By examining the subject curricula for classes, we encounter a number of repetitions and inaccuracies that greatly impede the planning and subsequent realization of the learning content by the teacher. As an example, we can point out the study of length way "arc" in VI and then again in IX class. In our opinion, this should be seen as a duplication of learning content, as the peculiarities of the learning process in motor activities and the psycho-physical mechanisms that regulate the formation of a motor habit do not allow a three-year break in the study of a technique. These regularities force the teacher to repeat VI class training at the beginning of IX class training, and only then continue with 
NAYDENOVA K.

the tactic of the leap to length and achieve the expected result, namely "Performs rational technique of stepping, jumping, flying and landing at jump in length. "

Another difference between the learning content and the peculiarities of the learning process in motor activity is noted in basketball. In V class, students should learn "dribbling" on the ball, and in grade VI a "left and right hand dribbling on the ground and on the move". Knowing the training method in a dribbling, it implies first performing the exercise on the spot with a comfortable and inconvenient hand, then performing in the same sequence in walking, light running, and so on. Examined in this way, in order to reach the expected result in the $\mathrm{V}$ grade students have to fulfil the learning content of the VI class curriculum.

In this direction, there are also a number of duplicates or skipping of learning content from one class to another, which is becoming a barrier for the teacher. It must either meet the requirements of the normative documents or follow the requirements of the training methodology.

Another normative change, which still has a significant effect on the subject "Physical Education and Sports", is the amendment to the Law on the level of education, the general educational minimum and the curriculum, published in SG, no. 40 of 2004 (5). The amendment of Art. 16, 5 reads "Each school week, in addition to the compulsory school hours under para. 2 also includes one lesson on the subject of "Physical Education and Sport", which is used for organizing and conducting sporting activities in the open. "The purely practical dimension of this change is having the so desired by all third hour of the subject. Besides the legal level, this class is also regulated by the Guidelines and Working Documentation for the third additional hour of the Physical education and Sport, issued by the Ministry of Education and Science in 2004. and Order № РД - 09 - 1038 of 27.07.2004 (6) of the Minister of Education and Science.

In these documents, the need for the third hour of "Physical Education and Sport" is substantiated by the aim of this class, which is defined as "focusing on the intentional motor activity and sport activity of learners, forming skills to become an integral part of the healthy way of Living " (Guidance and working documentation for the Physical Education and Sport third hour, 2004) (11). The organizational form for conducting this time is a module. However, the controversy follows in the same document, which states that "All modules are held outside the weekly timetable of the hours and on holiday and holiday days." This text, in fact, makes modular learning compulsory in a selective nature. The approach chosen by the state authorities for the implementation of these activities leads to the adoption of this school hour as optional by pupils and teachers. In most cases, it also takes place in the form of tourist activities, mainly trips or trips that take place once or twice a year. Consequently, the third school lesson of "Physical Education and Sport" does not fulfil its intended purpose and tasks.

It is a fact, however, that until today this class is not validated as a third subject, and with the entry into force of the Preschool and School Education Act it is even regarded as an "extra hour for sporting activities", which puts it away from the educational subject "Physical education and sport". As a positive, we can note the text of Art. 11, para 5 of Ordinance No. 10 of 01.09.2016 (10) on the organization of the activities in school education, issued by the Minister of Education and Science, which reads

"The training time for sports activities is included in weekly schedules beyond the number of classes according to the organization of the school day and the sports facilities in the school." The text so formulated makes the class mandatory.

\section{DISCUSSION}

The number of changes in the legal basis of education in the last almost 30 years have led to a number of changes in the structure and functioning of the education system in the country. With regard to the subject of "Physical Education and Sport", these changes can be defined as chaotic. Given the frequency of their occurrence, they lead to confusion among teachers and school principals. For example, there are still directors who do not enter the "Hours for organizing sporting activities" in the weekly schedule of classes, and teachers define this time as optional and optional for students.

The review and analysis of some basic normative documents gives us the basis to draw the following conclusions:

1. The already approved legal framework, which regulates the secondary education system in the country, is based on a 
qualitatively new approach in education, which leads to both structural and functional changes in the system.

2. The subject of "Physical education and sport" remains obligatory for all pupils at all stages and levels of the educational system, except for those who are trained under the "Dual Secondary education" system in the second high school stage.

3. In the approved curricula of Physical Education and Sport, there are multiple repetitions of the learning content in the different stages and grades, which is a prerequisite for loss of school hours and nonobservance of the principles and particularities of the training in motor activities.

The report also suggests one recommendation, namely that the hour for organizing sporting activities, should be approved, as one additional hour of "Physical Education and Sports", which will allow teachers to conduct systematic and purposeful training 3 or 4 hours a week.

\section{REFERENCES}

1. Borisov, L., Condition and functioning of the physical education system in the Republic of Bulgaria. Sofia: Bolid-Ins., 2017

2. Ivanov Sv .; Arakchijski Zdr .; Dimitrova N . Specificity of motor culture assessments in preschool children; Annual Scientific Conference 23.05. Sports, Society,
NAYDENOVA $K$.

Education Volume 2, NSA Press, Sofia, pp. 36-42, 1996

3. Act on National Education. (1991). MES.

4. Act on Preschool and School Education, Prom., SG, no. 79 of 13.10.2015, in force since 1.08.2016 (10 13, 2015).

5. Act on the level of education, the general educational minimum and the curriculum. (Promulgated in State Gazette No. 67 of 27.07.1999).

6. Order RD09 -1111 of 15.08 .2016 on the organization of hours for sports activities

7. Ordinance No 4 of 30 November 2015 on the curriculum Ordinance No 5 of 30.11.2015 on general education Prom. SG, No. 95 of 08.12.2015, in force as of 08.12.2015.

8. Ordinance amending and supplementing Ordinance No. 5 of 2015 on general education (SG 95/2015) Prom. - SG, No. 80 of 28.09.2018, in force as of 28.09.2018.

9. Ordinance No. 7 of 11.08.2016 on profiled training Prom. - SG, No. 67 of 26.08.2016, in force as of 26.08.2016.

10.Ordinance No. 10 of 01.09 .2016 on the organization of the activities in school education Prom. - SG, No. 73 of 16.09.2016, in force as of 01.09.2016

11.Guidance and working documentation for the Physical Education and Sport third hour, 2004

12.Curricula of "Physical Education and Sports" - from I to XII grade 